\title{
A cross sectional study on needle stick injuries, its associated factors and prophylactic measures among nursing staffs and students of a tertiary care hospital in Chennai
}

\author{
Rajesh J. ${ }^{1 *}$, Thamizhmaran S. ${ }^{2}$
}

DOI: https://doi.org/10.17511/ijphr.2019.i2.01

1* Rajesh J, Assistant Professor, Department of Community Medicine, Government Medical Collegea, Omandurar Government Estate,
Chennai, Tamil Nadu, Indiua.
2 S.P. Thamizhmaran, Final year MBBS student, Government Medical Collegea, Omandurar Government Estate, Chennai, Tamil Nadu, India.

Introduction: Nurses have the highest rate of Needle Stick Injuries (NSIs) among health care workers. Objectives: 1 . To determine the prevalence of NSIs in the past three months among nursing staffs and students of a Tertiary Care Hospital and the factors associated with it. 2 . To assess the pre and post exposure prophylactic measures related to NSIs followed by them. Methodology: This cross-sectional study was conducted between May and June 2017 among 354 subjects including 218 staff nurses and 136 nursing students of a Tertiary Care Government Hospital in Chennai City. After the Institutional Ethics Committee approval, subjects were interviewed with a pre-designed semi structured questionnaire. Data was analysed using relevant descriptive and inferential statistics with trial version of SPSS.v.25.0 Results: Prevalence of NSIs in the past three months was $29.7 \%(n=105)$. Majority $79(58.1 \%)$ nursing students had experienced NSIs. Two handed recapping of syringes was significantly associated with NSIs $(P=0.001$, OR $=4.363,95 \%$ C.I $=2.033-9.364)$. Around $40(38.1 \%)$ of the NSIs had occurred most commonly at the Inpatient wards. Majority 62 (59\%) of them had never reported about their NSI while only $25(23.8 \%)$ had reported regularly. Among those who got vaccinated with HBV vaccine $(n=57)$ for preexposure prophylaxis, only $13(22 \%)$ had taken three doses of HBV. Conclusion: Two handed recapping of syringes, non-usage of gloves, lack of assistance and inattentiveness during procedures, especially among nursing students are the major associated factors for occurrence of NSIs.

Keywords: Needle Stick Injuries (NSIs), Post-exposure Prophylaxis (PEP), Recapping of syringes, Safe Injection practices.

Corresponding Author

Rajesh J, Assistant Professor, Department of Community Medicine, Government Medical Collegea, Omandurar Government Estate, Chennai, Tamil Nadu, Indiua.

Email: rajeshjmails@gmail.com
How to Cite this Article

To Browse

Rajesh J, Thamizhmaran SP. A cross sectional study on needle stick injuries, its associated factors and prophylactic measures among nursing staffs and students of a tertiary care hospital in Chennai. Public Health Rev Int J Public Health Res. 2019;6(2):41-52. Available From https://publichealth.medresearch.in/index.php/ijphr/

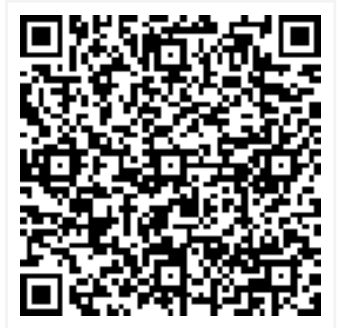
article/view/99

Manuscript Received 2019-03-04

Conflict of Interest No
Review Round 1 2019-03-14

Funding

Nil

Review Round 2
2019-03-20
Ethical Approval
Yes

Review Round 2

Yes
Review Round 3

Plagiarism X-checker $6 \%$
Accepted 2019-03-25

(C) 2019 by Rajesh J, S.P. Thamizhmaran and Published by Siddharth Health Research and Social Welfare Society. This is an Open Access article licensed under a Creative Commons Attribution 4.0 International License https://creativecommons.org/licenses/by/4.0/ unported [CC BY 4.0]. 


\section{Introduction}

The National Institute for Occupational Safety and Health (NIOSH), USA defines needle stick injuries as injuries caused by objects such as hypodermic needles, blood collection needles, intravenous (IV) stylets and needles used to connect parts of IV delivery systems [1]. Health-care workers are at increased risk of infection with blood borne pathogens because of occupational exposure to blood and other body fluids.

Most exposures among health-care workers are caused by percutaneous injuries with sharp objects contaminated with blood or body fluids. These sharps include needles, scalpels, lancets and broken glass. The pathogens most commonly transmitted to health-care workers in occupational settings are the hepatitis $B$ and $C$ viruses (HBV, HCV) and the human immunodeficiency virus (HIV) [2].

According to World Health Report 2002, of the 35 million health-care workers, 2 million experiences percutaneous exposure to infectious diseases each year [3].The rate of seroconversion after percutaneous exposure to HIV, HBV and $\mathrm{HCV}$ are $0.3 \%(0.18-0.46 \%), 18 \%(6-30 \%)$ and $1.8 \%$ $(0.1-7 \%)$ respectively [4]. More than $90 \%$ of these infections occur in developing countries but most of these NSIs remain unreported.

It is also found that $37.6 \%$ of Hepatitis $B, 39 \%$ of Hepatitis $C$ and $4.4 \%$ of HIV/AIDS in Health-Care Workers around the world are due to needle stick injuries [3]. These blood borne infections have serious consequences, including long-term illness, disability and death [4].

Occupational percutaneous exposures to blood borne pathogens can be prevented by strategies that include: immunization against HBV; procedures to prevent percutaneous injuries; and post-exposure prophylaxis (PEP) to prevent the development of disease [2].

Nurses have the highest rate of needle stick injury among health care workers [5]. Studies conducted Worldwide [6-9] as well as in India [10-15] among healthcare workers, have shown that reporting of NSIs and acceptance of PEP measures is among them is poor.

Hence this study has been planned to assess the burden of NSIs and its associated factors along with prophylactic measures practiced among staff nurses and nursing students of this Hospital who assist

\section{Objectives}

In patient care services. This would henceforth help to improve the health care delivery services being provided. With this background the study is proposed to be conducted with the following objectives:

01. To determine the prevalence of Needle Stick Injuries (NSIs) in the past three months among nursing staffs and students of a Tertiary Care Hospital and the factors associated with it.

02. To assess the pre and post exposure prophylactic measures related to Needle Stick Injuries followed by them.

\section{Methodology}

This cross-sectional study was conducted between May and June 2017 (two months) among the staff nurses and nursing students of a Tertiary Care Government Hospital in Chennai City. There were 232 staff nurses enrolled in the staff list of the Hospital and 198 nursing students. Among them, 218 staff nurses and 136 nursing students participated in the study.

Those study subjects who had more than three months of work experience in the Hospital were included as the study subjects. Informed Consent was obtained from all the study subjects, after explaining in detail about the study objectives and outcome. Those who were unwilling, and absentees during the period of study, were excluded. Prior approval for conducting the study was obtained from the Institutional Ethics Committee (IEC).

Data was collected by interview method with a predesigned and semi structured questionnaire based on World Health Organization (WHO) safe injection practices and National AIDS Control Organization (NACO) guidelines.

Data related to work experience, knowledge on blood borne infections, site, frequency, cause and mode of occurrence of injury, first aid measures done, universal precautions followed, pre-exposure Hepatitis B vaccination status and Post-Exposure Prophylaxis (PEP) measures taken were collected through the questionnaire. Data collected was coded and entered in Microsoft Office Excel Worksheet.

Statistical analysis using descriptive statistics like proportions, mean, median, standard deviation and inferential statistics like Chi-square test, Fisher's Exact test were done with trial version of 
SPSS.v.25.0.

\section{Results}

Among the 354 study subjects, majority $152(42.9 \%)$ were in the age group of $21-30$ years. There were 339 (95.8\%) females and 15(4.2\%) males. Of the study subjects there were 218 $(61.6 \%)$ staff nurses and $136(38.4 \%)$ were nursing students.

As shown in Table.1, among the 218 staff nurses only $26(11.9 \%)$ of them had experienced NSIs in the past three months while among the 136 nursing students, majority 79 (58.1\%) had experienced NSIs and this association was found statistically significant $(P=0.001$, OR $=0.098,95 \%$ C.I $=$ $0.057-0.166)$. Majority of the study subjects 210 $(59.3 \%)$ belonged to nuclear family.

There were 134 (37.9\%) day-scholars and 220 $(62.1 \%)$ hostellers. Among the 134 day scholars only $11(8.2 \%)$ had NSIs while among the 220 hostellers $94(42.7 \%)$ had NSIs and this association between residence and occurrence of NSIs was found statistically significant $(P=0.001$, $\mathrm{OR}=0.120,95 \%$ C.I $=0.061-0.235)$.

Of the total study participants majority of them 277 $(78.2 \%)$ had a total work experience of 1 -10years and in the present institution most of them 189 (53.4\%) had a work experience of less than one year. Among the study subjects majority 352 $(99.4 \%)$ were right handed persons. Occurrence of NSIs in the past three months was reported by 105 (29.7\%) among the 354 study subjects interviewed.

Of the 105 study subjects who had experienced NSIs in past the three months, majority 103 (30.4\%) were females while only 2 (13.3\%) were males. But this association between sex and NSI occurrence was not statistically significant ( $P=$ $0.247, \mathrm{OR}=0.353,95 \% \mathrm{CI}=0.057-0.166)$.

Table-1: Socio-demographic factors associated with Needle Stick Injuries (NSI):

\begin{tabular}{|c|c|c|c|c|}
\hline \multirow[t]{2}{*}{ Factors } & \multicolumn{2}{|r|}{ NSIs } & \multirow[t]{2}{*}{ Total $(N=354)$} & \multirow[t]{2}{*}{$P$ value } \\
\hline & Occurred & Not occurred & & \\
\hline \multicolumn{5}{|c|}{ Age category } \\
\hline$\leq 20 y r s$ & 75 (59.1) & $52(40.9)$ & 127 & \\
\hline $21-30$ yrs & $24(15.8)$ & $128(84.2)$ & 152 & \\
\hline $31-40$ yrs & $5(8.2)$ & $56(91.8)$ & 61 & $0.001 *$ \\
\hline 41-50yrs & $1(11.1)$ & $8(88.9)$ & 9 & \\
\hline$>50 \mathrm{yrs}$ & 0 & $5(100)$ & 5 & \\
\hline
\end{tabular}

\begin{tabular}{|c|c|c|c|c|}
\hline \multicolumn{5}{|l|}{ Sex } \\
\hline Male & $2(13.3)$ & $13(86.7)$ & 15 & 0.247 \\
\hline Female & $103(30.4)$ & $236(69.6)$ & 339 & \\
\hline \multicolumn{5}{|l|}{ Category } \\
\hline Staff Nurse & $26(11.9)$ & $192(88.1)$ & 218 & $0.001 *$ \\
\hline Nursing Student & 79 (58.1) & 57 (41.9) & 136 & \\
\hline \multicolumn{5}{|l|}{ Year of study } \\
\hline I Year nursing & $28(65.1)$ & 15 (34.9) & 43 & $0.001 *$ \\
\hline II Year nursing & $22(51.2)$ & $21(48.8)$ & 43 & \\
\hline III Year nursing & $29(58.0)$ & $21(42.0)$ & 50 & \\
\hline \multicolumn{5}{|l|}{ Family status } \\
\hline Nuclear & $81(38.6)$ & $129(61.4)$ & 210 & \\
\hline Joint & $18(13.3)$ & $117(86.7)$ & 135 & $0.001 *$ \\
\hline Three generation & $6(66.7)$ & $3(33.3)$ & 9 & \\
\hline \multicolumn{5}{|l|}{ Marital status } \\
\hline Single & $84(51.2)$ & $80(48.8)$ & 164 & \\
\hline Married & $21(48.8)$ & $166(88.8)$ & 187 & $0.001+$ \\
\hline Separated & 0 & $2(100.0)$ & 2 & \\
\hline Widow & 0 & $1(100.0)$ & 1 & \\
\hline \multicolumn{5}{|l|}{ Residence } \\
\hline Dayscholar & $11(8.2)$ & $123(91.8)$ & 134 & $0.001^{*}$ \\
\hline Hosteller & 94 (42.7) & $126(57.3)$ & 220 & \\
\hline
\end{tabular}

(Note: Figures in parenthesis denotes percentages; * - Pearson Chi-square test; +- Fisher's Exact test; $\mathrm{P}$ value $<0.05$ is considered as statistically significant)

Table-2: Distribution based on occurrence of NSIs:

\begin{tabular}{|l|l|}
\hline \multicolumn{1}{|c|}{ Factors } & \multicolumn{1}{|c|}{$\mathbf{n}(\%)$} \\
\hline NSI Experience (N = 354) & $105(29.7)$ \\
\hline Yes & $249(70.3)$ \\
\hline No & \multicolumn{2}{|l|}{} \\
\hline Frequency (n= 105) & $63(60.0)$ \\
\hline Once & $30(28.6)$ \\
Twice & $7(6.7)$ \\
Thrice & $4(3.8)$ \\
Four times & $1(1.0)$ \\
\hline Five times & $96(91.4)$ \\
\hline Site (n = 105) & $4(3.8)$ \\
\hline Upper limb & $8(6.8)$ \\
\hline Lower limb & $7(6.7)$ \\
Not sure & $72(68.6)$ \\
\hline Type NSI (n= 105) & $11(10.5)$ \\
\hline Pierced & $15(14.3)$ \\
\hline Puncture & $50(47.6)$ \\
Cut & $38(36.2)$ \\
Scratch & $17(16.2)$ \\
\hline Instrument (n= 105) & \multicolumn{2}{|l|}{} \\
\hline Sterile instrument & Non instrument \\
Both & \\
\hline
\end{tabular}




\begin{tabular}{|l|l|}
\hline \multicolumn{2}{|l|}{ Time of occurrence $(\mathbf{n}=\mathbf{1 0 5})$} \\
\hline Day & $59(56.2)$ \\
Afternoon & $13(12.4)$ \\
Evening & $11(10.5)$ \\
Night & $7(6.7)$ \\
Not sure & $15(14.3)$ \\
\hline
\end{tabular}

Table 2 shows that, among those who had NSIs $(n=105)$ majority $63(60 \%)$ had experienced at least once, followed by $30(28.6 \%)$ of them who had experienced at least twice. Of the reported NSIs the major site of occurrence was upper extremity 96 ( $91.4 \%)$ followed by lower extremity 4 (3.8\%).

Majority $72(68.6 \%)$ of the NSIs were Punctured wounds whereas pierced wounds were the least common $7(6.7 \%)$ type of NSIs. Most of the NSIs, $50(47.6 \%)$ were caused due to a sterile instrument followed by non-sterile instruments 38 (36.2\%). Maximum 59 (56.2\%) of the NSIs had occurred during daytime while only $7(6.7 \%)$ of the injuries had occurred during night.

(Note: Figures in parenthesis denotes percentages)

Table. 3 shows that, Recapping the syringes by 21 $(20.0 \%)$ subjects was the most common cause of NSIs followed by administration of an I.M injection $17(16.2 \%)$ and $13(12.4 \%)$ after administering an I.V injection and least 2 (1.9\%) while blood withdrawal and $1(0.9 \%)$ had while suturing. Among the type of needles that caused the NSIs needle of disposable syringe were most common 76 (72.4\%) while only $4(3.8 \%)$ of them were injured by needle of auto-disable syringes.

Of the various reasons for occurrence of NSIs reported, majority $22(21 \%)$ were due to inattentiveness during a procedure followed by 21 $(20 \%)$ of them due to procedures during an emergency situation. As shown in Fig.1, In-patient wards were the most common 40 (38.1\%) location where NSIs had occurred in the hospital while only $3(2.9 \%)$ had occurred in OTs.

Table-3: Distribution based on procedures, instruments and reasons for NSIs:

\begin{tabular}{|c|c|}
\hline Factors & $n(\%)$ \\
\hline \multicolumn{2}{|c|}{ Procedure that Caused a NSI $(n=105)$} \\
\hline Blood withdrawal & $2(1.9)$ \\
\hline Recapping & $21(20.0)$ \\
\hline Suturing & $1(1.0)$ \\
\hline vaccination & $6(5.7)$ \\
\hline Sample collection & $5(1.9)$ \\
\hline Transfer of sample & $2(1.9)$ \\
\hline Accessing IV cannulation & $9(8.6)$ \\
\hline
\end{tabular}

\begin{tabular}{|c|c|}
\hline & \\
\hline Administering IM injection & $17(16.2)$ \\
\hline Administering IV injection & $13(12.4)$ \\
\hline Administering SC injection & $4(3.8)$ \\
\hline Administering ID injection & $1(1.0)$ \\
\hline Disassembling a device & $13(12.4)$ \\
\hline Biomedical waste handling & $12(11.4)$ \\
\hline Others & $15(14.3)$ \\
\hline Specific instrument-nee & \\
\hline Disposable syringe & 76 (72.4) \\
\hline Auto disable syringe & $4(3.8)$ \\
\hline Scalp vein set & $7(6.7)$ \\
\hline IV set & $8(7.6)$ \\
\hline Others & $2(1.9)$ \\
\hline Not sure & $8(7.6)$ \\
\hline Presumed Cause for NSI & \\
\hline In-attentiveness & $22(21.0)$ \\
\hline Inflicted by colleague & $6(5.7)$ \\
\hline Self-inflicted & $12(11.4)$ \\
\hline Poor visibility & $2(1.9)$ \\
\hline Inadequate space & $4(3.8)$ \\
\hline Hurried-late & $20(19.0)$ \\
\hline Hurried-emergency & $21(20.0)$ \\
\hline Patient aggressiveness & $7(6.7)$ \\
\hline Others & $1(1.0)$ \\
\hline Not sure & $20(19.0)$ \\
\hline Presumed reason for NS & \\
\hline Fatigue & $22(21)$ \\
\hline Vision problems & $4(3.8)$ \\
\hline Lack of guidance & $4(3.8)$ \\
\hline Lack of training & $1(1.0)$ \\
\hline Lack of assistance & $24(22.9)$ \\
\hline Lack of experience & $14(13.3)$ \\
\hline Others & 36 (34.3) \\
\hline
\end{tabular}

(Note: Figures in parenthesis denotes percentages)

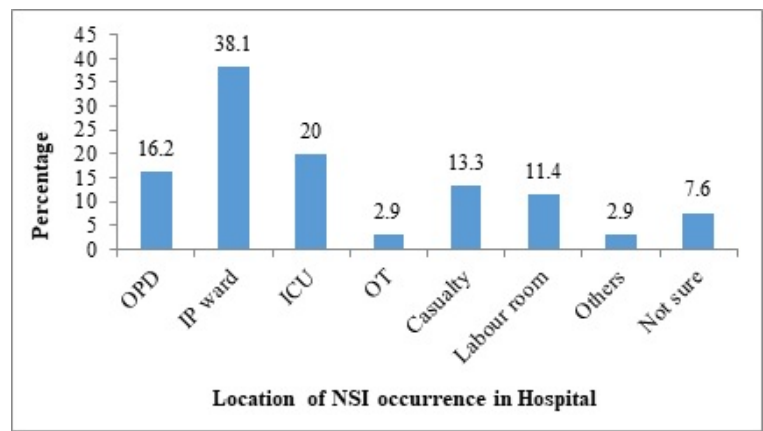

Fig. 1: Distribution based on the Location of NSI occurrence in Hospital $(n=105)$

It is seen from table.4, immediately following the NSIs maximum $90(85.7 \%)$ of them had washed their injured site as a first aid measure of which mostly 41 (45.5\%) had washed with spirit. Among the study subjects $3(2.9 \%)$ had sucked the injured 
Site following an injury.

After the NSIs majority 78 (74.3\%) had carried on their duty as usual while $6(5.7 \%)$ of them had cried or left their work location immediately. Of the various probable reasons cited for NSIs mostly 24 $(22.9 \%)$ of them had reasoned NSIs due to lack of assistance followed by $22(21.0 \%)$ of them to fatigue while $4(3.8 \%)$ to problems in vision and lack of guidance in safe injection practices.

Reporting following a NSI is an important factor in analysis of the seriousness of the NSI and to decide upon the appropriate Post-exposure prophylactic measure. Of the study subjects who had NSIs majority 62 (59.0\%) of them had never reported about the NSI while only 25 (23.8\%) had reported regularly and $18(17.1 \%)$ had reported occasionally.

Among those who reported NSIs $(n=53)$ majority 27 (50.9\%) had reported immediately while 10 (18.8 $\%)$ of them had reported later than a week and only $6(11.3 \%)$ of them had reported within a week of occurrence of NSIs.

Of those who had reported of their NSIs $(n=53)$ maximum 31 (58.4\%) had reported it to their senior nursing staff and 17 (32\%) to their colleagues while only 5 (9.4\%) of them had reported to ICTC.

Table-4: Distribution based on measures taken following a NSI:

\begin{tabular}{|c|c|}
\hline Fac & n $(\%)$ \\
\hline \multicolumn{2}{|l|}{ First aid done $(n=105)$} \\
\hline Ignored & $7(6.7)$ \\
\hline squeeze & $14(13.3)$ \\
\hline Sucked & $3(2.9)$ \\
\hline Did nothing & $5(4.8)$ \\
\hline Not sure & $3(2.9)$ \\
\hline Washed & $90(85.7)$ \\
\hline \multicolumn{2}{|c|}{ Washed NSI site with $(n=90)$} \\
\hline With Water & $17(18.8)$ \\
\hline With Soap & $9(10.0)$ \\
\hline With Spirit & $41(45.5)$ \\
\hline With Antiseptic & $23(25.5)$ \\
\hline \multicolumn{2}{|c|}{ Reaction following a NSI $(n=105)$} \\
\hline Cried & $6(5.7)$ \\
\hline Called for help & $11(10.5)$ \\
\hline Left work area immediately & $6(5.7)$ \\
\hline Carried duty as usual & $78(74.3)$ \\
\hline Others & $4(3.8)$ \\
\hline \multicolumn{2}{|l|}{ Reporting of NSI $(n=105)$} \\
\hline Yes regularly & $25(23.8)$ \\
\hline Yes occasionally & $18(17.1)$ \\
\hline Never & $62(59.0)$ \\
\hline
\end{tabular}

\begin{tabular}{|l|l|}
\hline \multicolumn{2}{|l|}{ Timing of reporting a NSI $(\mathbf{n}=\mathbf{5 3})$} \\
\hline Immediately & $27(50.9)$ \\
Within a day & $10(18.8)$ \\
Within a week & $6(11.3)$ \\
Later than a week & $10(18.8)$ \\
\hline Person to whom NSI was reported (n = 53) \\
\hline Senior staff nurses & $31(58.4)$ \\
ICTC & $5(9.4)$ \\
Others & $17(32.0)$ \\
\hline
\end{tabular}

(Note: Figures in parenthesis denotes percentages)

Of the total 354 study subjects, 337 (95.2\%) knew that certain diseases were transmitted by NSIs. Of them $(n=337), 321 \quad(90.7 \%)$ knew HIV, 201 (56.8\%) knew HBV and 123 (34.7\%) knew HCV could be transmitted by NSIs, as shown in Fig. 2. Majority $273(77.1 \%)$ members of the total study subjects knew that Post exposure prophylaxis (PEP) measures were available for NSIs.

Among those who had NSIs ( $n=105)$, most of them 38 (35.2\%) had not got assessed for PEP following NSIs followed by 31 (29.5\%) who had self-investigated without reporting while only 12 (11.4\%) of them got assessed for PEP following a NSI.

From table. 5 it is evident that, of those who had NSIs ( $n=105), 57$ (53.3\%) had been vaccinated with HBV as Pre-exposure prophylaxis, of which only $13(22.8 \%)$ had taken all the three doses of HBV.

Among those who had NSIs ( $n=105$ ), only 15 $(14.2 \%)$ had been vaccinated with HBV as a PEP measure of which only $3(20.0 \%)$ of them had taken three doses of HBV vaccine. Around 33 (31.4 $\%$ ) study subjects had never taken HBV vaccine for prophylaxis. Of those 105 subjects who had NSIs, $37(35.2 \%)$ of them knew about the HBV status of their source and $43(41.0 \%)$ of them knew about the HIV status of their source.

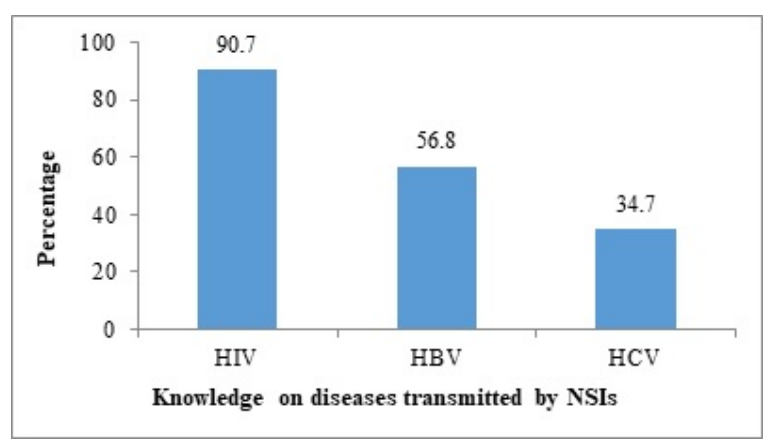

Fig.-2: Distribution based on Knowledge on diseases transmitted by NSIs $(N=354)$ 
Of those who got assessed for NSIs $(n=12)$, only 2 (16.6\%) were prescribed PEP and had completed the course of PEP for HIV.

\section{Table-5: Distribution based on Prophylactic} measures taken for NSIs:

\begin{tabular}{|c|c|}
\hline Factors & n (\%) \\
\hline \multicolumn{2}{|c|}{ Awareness on PEP for NSI $(N=354)$} \\
\hline Yes & $273(77.1)$ \\
\hline No & $81(22.9)$ \\
\hline \multicolumn{2}{|l|}{ Assessment for PEP $(n=105)$} \\
\hline Done & $12(11.4)$ \\
\hline Not done & $38(35.2)$ \\
\hline Don't know & $24(22.9)$ \\
\hline Self-investigated without reporting & $31(29.5)$ \\
\hline \multicolumn{2}{|c|}{ Immunoprophylaxis for HBV $(n=105)$} \\
\hline Took pre exposure prophylaxis & $57(53.3)$ \\
\hline Took post exposure prophylaxis & $15(14.2)$ \\
\hline Never & $33(31.4)$ \\
\hline \multicolumn{2}{|c|}{ No. of Pre exposure doses of HBV vaccine taken $(n=57)$} \\
\hline 1 dose & $12(21.1)$ \\
\hline 2 dose & $32(56.1)$ \\
\hline 3 dose & $13(22.8)$ \\
\hline \multicolumn{2}{|c|}{ No. of Post exposure doses of HBV vaccine taken $(n=15)$} \\
\hline 1 dose & $7(46.6)$ \\
\hline 2 dose & $3(20.0)$ \\
\hline 3 dose & $3(20.0)$ \\
\hline Booster & $2(13.3)$ \\
\hline \multicolumn{2}{|l|}{ HBV Status of the source $(n=105)$} \\
\hline Known & $37(35.2)$ \\
\hline
\end{tabular}

\begin{tabular}{|l|l|}
\hline Unknown & $68(63.8)$ \\
\hline \multicolumn{2}{|l|}{ HIV Status of the source $(\mathbf{n}=\mathbf{1 0 5})$} \\
\hline Known & $43(41.0)$ \\
Unknown & $62(59.0)$ \\
\hline PEP for HIV ( $\mathbf{n}=\mathbf{1 0 5})$ & $22(21.0)$ \\
\hline Not necessary & $2(1.9)$ \\
Yes & $81(76.2)$ \\
\hline No & $2(100)$ \\
\hline Course completion of PEP for HIV(n=2) \\
\hline Completed & 0 \\
\hline Not completed
\end{tabular}

(Note: Figures in parenthesis denotes percentages)

Safe injection practices are primarily involved in preventing the occurrence of NSIs. Among the total study participants $(\mathrm{N}=354)$,

$136(38.4 \%)$ of them used gloves always before an injection of which only $19(14.0 \%)$ of them had experienced NSIs while among the 24 subjects who never used gloves 14 (58.3\%) had experienced NSIs.

This association between non-usage of gloves and NSIs was found to be statistically significant $(P=$ 0.001). Of the study participants $(N=354)$, majority 256 (72.3\%) had destroyed the needle safely by a hub cutter followed by 76 (21.5\%) who had disposed them in a puncture proof container while at least $31(8.8 \%)$ of them recapped the needle with two hands in an unsafe manner.

Table-6: Distribution based on factors associated with NSIs

\begin{tabular}{|c|c|c|c|c|c|c|c|}
\hline \multirow[t]{2}{*}{ NSI associated factors } & \multicolumn{2}{|r|}{ NSIs } & \multirow[t]{2}{*}{ Total $(N=354)$} & \multirow[t]{2}{*}{ P value } & \multirow[t]{2}{*}{$\mathbf{X}_{2}$} & \multirow[t]{2}{*}{ OR } & \multirow[t]{2}{*}{$95 \% \mathrm{CI}$} \\
\hline & Occurred & Not occurred & & & & & \\
\hline \multicolumn{8}{|c|}{ Work experience in present hospital } \\
\hline$<1$ year & $49(25.9)$ & $140(74.1)$ & 189 & 0.104 & 2.711 & 0.681 & $0.431-1.077$ \\
\hline$\geq 1$ year & $56(33.9)$ & $109(66.1)$ & 165 & & & & \\
\hline \multicolumn{8}{|l|}{ Total Work experience } \\
\hline$<10$ years & $103(31.9)$ & $219(68.01)$ & 322 & $0.002 *$ & 9.242 & 7.055 & $1.654-30.087$ \\
\hline$\geq 10$ years & $2(6.3)$ & $30(93.8)$ & 32 & & & & \\
\hline \multicolumn{8}{|l|}{ Handedness M } \\
\hline Right & $105(29.8)$ & $247(70.2)$ & 352 & 0.0582 & 0.848 & 0.702 & $0.656-0.751$ \\
\hline Left & 0 & $2(100.0)$ & 2 & & & & \\
\hline \multicolumn{8}{|l|}{ Glove usage } \\
\hline Sometimes & $72(37.1)$ & $122(62.1)$ & 194 & & & & \\
\hline Never & $14(58.3)$ & $10(41.7)$ & 24 & & & & \\
\hline \multicolumn{8}{|l|}{ One handed recapping } \\
\hline Yes & $2(22.2)$ & $7(77.8)$ & 9 & 0.621 & 0.245 & 0.671 & $0.137-3.286$ \\
\hline No & $103(29.9)$ & $242(70.0)$ & 345 & & & & \\
\hline
\end{tabular}




\begin{tabular}{|c|c|c|c|c|c|c|c|}
\hline \multicolumn{8}{|c|}{ Two handed recapping } \\
\hline Yes & $19(61.3)$ & $12(38.7)$ & 31 & $0.001 *$ & 16.291 & 4.363 & $2.033-9.364$ \\
\hline No & $86(26.6)$ & $237(73.4)$ & 323 & & & & \\
\hline \multicolumn{8}{|l|}{ Hub cutter } \\
\hline Yes & $74(28.9)$ & $182(71.1)$ & 256 & 0.615 & 0.252 & 0.879 & $0.531-1.455$ \\
\hline No & $31(31.6)$ & $67(68.4)$ & 98 & & & & \\
\hline \multicolumn{8}{|c|}{ Puncture proof container used } \\
\hline Yes & $12(15.8)$ & $64(84.2)$ & 76 & $0.003 *$ & 8.926 & 0.373 & $0.192-0.725$ \\
\hline No & $93(33.5)$ & $185(66.6)$ & 278 & & & & \\
\hline \multicolumn{8}{|c|}{ Disposal in a nearby bin } \\
\hline Yes & $2(100)$ & 0 & 2 & 0.087 & 4.770 & 3.417 & $2.905-4.020$ \\
\hline No & $103(29.3)$ & $249(70.7)$ & 352 & & & & \\
\hline \multicolumn{8}{|c|}{ Posters on Injection safety } \\
\hline Sufficiently & $52(27.4)$ & $138(72.6)$ & 190 & 0.576 & 1.102 & & \\
\hline Rarely & $28(31.5)$ & $61(68.5)$ & 89 & & & & \\
\hline Not available & $25(33.3)$ & $50(66.7)$ & 75 & & & & \\
\hline \multicolumn{8}{|c|}{ Injection safety training } \\
\hline Yes & $62(32.0)$ & $132(68.0)$ & 194 & 0.297 & 1.086 & 1.278 & $0.805-2.028$ \\
\hline No & $43(26.9)$ & $117(73.1)$ & 160 & & & & \\
\hline
\end{tabular}

(Note: Figures in parenthesis denotes percentages; ${ }^{*}$ - Pearson Chi-square test; $\mathrm{P}$ value $<0.05$ is considered as statistically significant)

Among those 76 subjects who had disposed the syringe in a puncture proof container, only 12 $(15.8 \%)$ of them had NSIs while 93 (33.5\%) of the 278 subjects who did not dispose the needle in a puncture proof container had experienced NSIs and this association between usage of puncture proof container and prevention of NSIs was found to be statistically significant $(P=0.003, O R=0.373,95$ $\%$ C.I $=0.192-0.725)$.

As shown in table.6, among those 31 subjects who had recapped the syringe using two hands, NSIs had occurred in $19(61.3 \%)$ of them. There exists a statistically significant association between recapping of syringes with two hands and occurrence of NSIs ( $P=0.001$, OR $=4.363,95 \%$ C.I $=2.033-9.364)$.

Of all the study subjects, majority 190 (53.7\%) had reported that sufficient awareness posters on safe injection practices were available in their work place. In total, maximum 194 (54.8\%) subjects had undergone dedicated training on safe injection practices of which, majority 138 (71.1\%) had attended lecture on safe injection practices while only $37(19 \%)$ of them had ever undergone a hands-on training workshop on safe injection practices.

But the association between training on safe injection practices and occurrence of NSIs was not statistically significant. $(P=0.297, O R=1.278,95$
$\%$ C.I $=0.805-2.028)$

\section{Discussion}

In the present study majority $59.1 \%$ of the NSIs had occurred in the age group of 20 years or less but the study done by Kruger et al [8] had reported that $40.6 \%$ had occurred in the age group of 21-30 years. Inclusion of nursing students in our study could be a reason behind this difference. NSIs decreases with years of work experience.

In our study, those with a total work experience of 10 years or less had more NSIs (31.9\%) in similar to the study of Laishram J et al [16]. In our study prevalence of NSI was $29.7 \%$ which was in similar to Laishram J et al [16] study which reported NSI prevalence among nurses as $28.1 \%$.

Also majority of the study subjects had encountered NSIs atleast once in both the studies. NSIs occur most often in fingers. As found in our study where $80 \%$ of NSIs occurred in fingers Rais $N$ et al [17] reported in $72.7 \%$ of the cases.

In our study majority $21 \%$ had perceived that NSIs occurred due to their inattentiveness followed by 20 $\%$ due to procedures done in an emergency. Similarly Nagandla $\mathrm{K}$ et al [18] have reported that $52.6 \%$ of the NSIs occurred during emergency care procedures. 
Recapping of the needle is a major cause for NSIs. Especially two handed recapping has more risk over one handed recapping technique. As reported in our study where $20.0 \%$ of the NSIs occurred during recapping of the needle, most other studies $[19,20,21]$ in India and worldwide have reported recapping as the most common cause of NSIs.

In our study, most of the NSI (38.1\%) had occurred at the In-patient wards which was in similar to the studies of Rais $\mathrm{N}$ et al [17] (41.6\%) and Buraidah A.Q et al [22] (42.5\%). In our study, majority $22.9 \%$ of the NSIs occurred due to lack of assistance, similar to $23.3 \%$ in Laishram J et al [16] study.

In Rogers B et al [23] study, it has been shown that lack of experience in many procedures, insufficient training and fatigue leads to occupational sharp injuries. In our study $23.8 \%$ of them reported their NSI regularly while $59 \%$ did not report their NSI. Only $12 \%$ of them reported the NSIs regularly in Mohapatra D et al [24] study whereas $80 \%$ of them reported in Beker J et al [7].

95.2\% had known that the diseases were transmitted by NSI similar to Beker J et al [7] study (92.9\%). In our study $90.7 \%$ knew about HIV, $56.8 \%$ knew about HBV and $34.7 \%$ knew about $\mathrm{HCV}$ as the diseases transmitted by NSIs this was higher when compared to Laishram J et al [16] study where only $72.1 \%, 29.1 \%$ and $19.8 \%$ knew about HIV, HBV and HCV respectively.

In our study, of the 105 subjects who had NSIs, only $11.4 \%$ of them had got assessed for their NSIs whereas it was $20 \%$ of them as reported by Rajput PS et al [19] study. Our study reported that $53.3 \%$ were vaccinated with HBV vaccine as a preexposure prophylaxis whereas Kruger et al [8] had reported as $89.6 \%$. In our study $14.2 \%$ had been vaccinated with HBV as a PEP measure while $31.4 \%$ had never been vaccinated with HBV.

In contrast, Rajput PS et al [19] study shows that $11.2 \%$ of them had HBV vaccine as a PEP measure while only $21.2 \%$ of them had never been vaccinated for HBV. This shows the need for increase in awareness on prophylaxis for HBV among our nurses.

In our study only $20 \%$ of them had taken all three doses of HBV vaccine as PEP whereas Kruger et al [8] have reported that $60.2 \%$ had taken all three doses of HBV vaccine which shows the need to improve adherence to vaccination schedule among
Our nurses.

The study done by Mohapatra D et al [24] showed that $46 \%$ of them knew about the HIV status of their source in similar to our study where $41 \%$ of them knew about the HIV status of their source. In our study $38.4 \%$ of them had used gloves always before an injection while Mohapatra $D$ et al [24] showed that $43 \%$ had used gloves always.

In our study majority $72.3 \%$ had destroyed the needle safely by a hub cutter while only $21.5 \%$ had disposed them in a puncture proof container whereas Karthik et al [25] study had reported only $21 \%$ had used a hub cutter while $65 \%$ had disposed them in a puncture proof container. In our study only $8.8 \%$ of them had recapped with two hands in an unsafe manner whereas Rais $\mathrm{N}$ et al [17] study had reported it to be $42 \%$.

In our study $54.8 \%$ of them had undergone dedicated training on safe injection practices while Laishram J et al [16] study had reported it to be $69.9 \%$. So there is a need to increase those trained in safe injection practices.

\section{Conclusion}

NSIs poses an important occupational hazard for health care workers, especially for the nursing personnel who are involved in day to day bedside medical care procedures like administration of injections, intravenous cannulations, blood sample collection etc. Two handed recapping of syringes, non-usage of gloves, lack of assistance and inattentiveness during procedures, especially among nursing students are the major associated factors for occurrence of NSIs.

Increase in awareness on diseases transmitted by NSIs, its pre-exposure and post-exposure prophylactic measures, need for reporting for immediate assessment of NSIs, compliance towards prophylactic measures and periodic hands on training on safe injection practices for nursing students and staff nurses would reduce the occurrence of NSIs and thereby the diseases transmitted due to them.

\section{Reference}

01. NIOSH. Preventing needlestick injuries in health care settings, US Department of health and human services. Cincinnati- DHHS (NIOSH). 1999.

[Crossref] 
02. Prüss-Üstün A, Rapiti E, Hutin Y. Sharps injuriesglobal burden of disease from sharps injuries to health-care workers. WHO, Environmental Burden of Disease Series, No 3. 2003.

[Crossref]

03. WHO. Reducing risks, promoting healthy life. Geneva. 2002. Available from:

[Article] [Crossref]

04. Rapiti, E, Prüss-Üstün, A, Hutin, Y. Sharps injuries- assessing the burden of disease from sharps injuries to health-care workers at national and local levels. WHO, Environmental Burden of Disease Series, No 11. 2005. [Crossref]

05. ICN on Preventing Needle stick Injuries. Nursing Matters- Fact sheets. 2009.

Available from: [Article] [Crossref]

06. Zhang X, Gu Y, Cui M, et al. Needlestick and Sharps Injuries Among Nurses at a Teaching Hospital in China. Workplace Health Saf. 2015 May;63(5)219-25.

doi: [Article] [Crossref]

07. Beker J, Bamlie T. Needle Stick and Sharp Injuries and Associated Factors among Nurses Working In Jimma University Specialized Hospital, South West Ethiopia. J Nurs Care. $2015 ; 4 ; 291$.

doi: [Article] [Crossref]

08. Kruger $\mathrm{WH}$, Jimoh SO, Joubert G. Needlestick injuries among nurses in a regional hospital in South Africa. Occupational Health Southern Africa. 2012;18(3)04-10.

[Crossref]

09. Smith DR, Leggat PA, Takahashi K. Percutaneous Exposure Incidents Among Australian Hospital Staff. International Journal of Occupational Safety and Ergonomics. 2005; 11(3)323-330.

[Crossref]

10. Muralidhar S, Singh PK, Jain RK, et al. Needle stick injuries among health care workers in a tertiary care hospital of India. Indian J Med Res. 2010 Mar; 131;405-10.

[Crossref]

11. Priyanka, Acharya AS, Khandekar J, Sharma A. Awareness and practices regarding needle stick injuries among nurses in a tertiary care hospital of Delhi. Ind J Comm Health. 2014;26(4)390-5. [Crossref]
12. Bhattacharya A, Basu M, Das P. The pattern of needle stick injury among health care workers at West Bengal. Muller J Med Sci Res. 2014;5;29-33.

[Crossref]

13. Jain C, Waskel B, Bansal SB, Jesani $M$. Prevalence of needle stick injuries among paramedical staff- a cross sectional study at a tertiary level hospital in Indore. Int J Community Med Public Health. 2016;3;1379-82. [Crossref]

14. Holla $R$, Unnikrishnan $B$, Ram $P$, Thapar R, Mithra $P$, et al. Occupational Exposure to Needle Stick Injuries among Health Care Personnel in a Tertiary Care Hospital- A Cross Sectional Study. J Community Med Health Educ. 2014;S2;004. doi: [Article] [Crossref]

15. Sureshkumar D, Ramasubramanian V, Abdulghafur $K$. Needle stick injuries among health care workers - a report from India. BMC Proceedings. $2011 ; 5(6) 225$.

[Crossref]

16. Laishram J, Keisam A, Phesao E, Tarao MS, Laloo VJ, Devi HS. Prevalence of needle stick injuries among nurses in a tertiary care hospital and their immediate response. Int J Med Public Health. 2013;3;257-60.

[Crossref]

17. Rais $\mathrm{N}$ and Jamil HM. Prevalence of needle stick injuries among the health care providers. International journal of endorsing health science research. 2013;1(2)73-79.

[Crossref]

18. Nagandla K, Kumar K, Bhardwaj A, Devalagan, Yhmin C, Lun LW, Shi WW et al. Prevalence of needle stick injuries and their underreporting among healthcare workers in the department of obstetrics and gynaecology. International Archives of Medicine. 2015;8(181)1-16. [Article] [Crossref]

19. Rajput PS, Doibale MK, Sonkar VK, Inamdar IF, Nair A, Shingare AD. Prevalence of Needle Stick Injuries and Associated Risk Factors among Nurses in a Tertiary Care Hospital. Int J Prevent Public Health Sci. 2016;1(5)16-19.

[Crossref]

20. Kaushik A, Sarin J. Prevalence of Needle stickInjuries and Its Related Factors Among Nurses. IOSR Journal of Nursing and Health Science. 2015;4(5)01-06.

¡Crossref] 
21. Jahangiri M, Rostamabadi A, Hoboubi N, Tadayon N, Soleimani A. Needle Stick Injuries and their Related Safety Measures among Nurses in a University Hospital, Shiraz, Iran. Safety and Health at Work. 2016;72-77.

Available from: [Article] [Crossref]

22. Buraidah AQ. Epidemiology of needlestick injuries among health care workers in a secondary care hospital in Saudi Arabia. Ann Saudi Med. 2005;25(3)233-38.

[Crossref]

23. Rogers B, Goodno L. Evaluation of interventions to prevent needlestick injuries in health care occupations. Am J Prev Med. 2000 May;18(4 Suppl)90-8.

[Crossref]
24. Mohapatra D, Gupta V, Malik JS. A study on Needle Stick Injury among nursing staff of a Tertiary Care Hospital of Haryana. Journal of Advanced Research in Medicine. April 2015;2(1)5-9.

[Crossref]

25. Karthik RC, Uma Devi R, Gopalakrishnan S, Raja S, and Rama R. A Study on Knowledge And Practices Related To Safe Injection Practices Among Nursing Students In A Tertiary Care Hospital, Chennai, Tamil Nadu, India. Research Journal of Pharmaceutical, Biological and Chemical Sciences. 2015;6(5)857-62. [Crossref] 